\title{
A pesquisa-intervenção em Psicologia do Trabalho em um aporte que toma o desenvolvimento como método e objeto ${ }^{\star}$
}

\author{
Claudia Osório da Silva, ${ }^{\star}$ Alice Paiva Souto, Karla Maria Neves Memória-Lima \\ Universidade Federal Fluminense, Niterói, RJ, Brasil
}

\begin{abstract}
Resumo
O Núcleo de Estudos e Intervenção em Trabalho, Subjetividade e Saúde (Nutras) é um grupo de pesquisa vinculado à Universidade Federal Fluminense. Uma de suas linhas de pesquisa tem como objeto o trabalho como operador de saúde. A principal referência teórica é a corrente da psicologia do trabalho chamada clínica da atividade, fundada na psicologia histórico-cultural de Vigotski, em intercessão com outras teorias como a linguística de Bakhtin (2006) e a ergonomia situada francofônica (WISNER, 1995). Numa abordagem clínica do trabalho, toma o conceito de desenvolvimento como central, utilizando-o como método para uma intervenção dialógica a Oficina de Fotos.
\end{abstract}

Palavras-chave: trabalho; atividade; desenvolvimento.

\section{The intervention-research in Work Psychology in a contribution that takes development as method and object}

\begin{abstract}
The Nucleus of Studies and Intervention in Work, Subjectivity and Health (Nutras) is a research group linked to Fluminense Federal University in Rio de Janeiro, Brazil. One of its lines of research focuses work as an operator of health. The main theoretical reference is the psychology current called Clinic Of Activity, funded in Vigotski's historical-cultural psychology, in intercession with other theories as Bakhtin's linguistics and Francophone ergonomics (WISNER, 1995). In a clinical approach to work, it takes the concept of development as central and has been using the Photography Workshop as a method for dialogic intervention.
\end{abstract}

Keywords: work; activity; development.

\section{Apresentação}

Em 2004, foi criado na Universidade Federal Fluminense o grupo de pesquisa intitulado Núcleo de Estudos e Intervenção em Trabalho, Subjetividade e Saúde - Nutras. Uma de suas linhas de pesquisa tem como objeto o trabalho como operador de saúde. A principal referência teórica é a corrente da psicologia do trabalho chamada clínica da atividade, fundada na psicologia histórico-cultural de Vigotski, em intercessão com outras teorias como a linguística de Bakhtin (2006) e a ergonomia situada francofônica (WISNER, 1995). Nessa intercessão, o conceito de atividade (de trabalho) é central. O objeto nesta linha de pesquisa é o trabalho nas organizações brasileiras, públicas e privadas, na sua relação com as ações dos setores de gestão do trabalho. Tem como objetivo estudar os efeitos de produção de saúde ou, inversamente, de redução da saúde, sobre os trabalhadores, no trabalho contemporâneo em organizações brasileiras de grande e médio porte. O conceito de saúde é tomado de Georges Canguilhem (2012).

A produção do Nutras é marcada por estudos relacionados ao trabalho na rede do Sistema Único de Saúde e na rede pública de educação no Brasil. Esses estudos têm como objetivo analisar os problemas de gestão dos serviços, tendo como central o ponto de vista da atividade dos trabalhadores e dando especial atenção à saúde dos pro-

^ Grupo de Pesquisa Núcleo de Estudos e Intervenção em Trabalho, Subjetividade e Saúde (NUTRAS), coordenado por Cláudia Osório da Silva.

$\star \star$ Endereço para correspondência: Universidade Federal Fluminense, Centro de Estudos Gerais. Campus do Gragoatá Bloco O sala 310 - São Domingos. 24210 200 - Niteroi, RJ - Brasil.E-mail: cosorio@vm.uff.br, ally paiva@yahoo.com. br, karla.memoria@gmail.com fissionais de saúde. A partir de 2010, a produção do grupo passou a incorporar estudos em organizações públicas e privadas de outros setores, tais como petroquímica, coleta de lixo, eletricidade e outros.

A linha de pesquisa Trabalho como operador de saúde tem desenvolvido estudos de método, dedicando-se em especial ao desenvolvimento de um dispositivo intitulado Oficina de Fotos. Na proposta teórico-metodológica adotada, a análise do trabalho tem como protagonista $\mathrm{o}$ trabalhador, com o objetivo de desenvolvimento de recursos coletivos e individuais para o trabalho. Os métodos são indiretos, tal como proposto por Vigotski. E a unidade de análise é a atividade.

Essa linha de pesquisa é integrada pelas professoras Ana Paula Lopes e pelas autoras deste artigo. As professoras Ana Paula Lopes e Claudia Osório são ambas vinculadas ao Departamento de Psicologia da UFF. O Nutras é composto também por colegas da Universidade Federal do Espírito Santo, ligados ao Departamento de Psicologia e ao Programa de Pós-Graduação em Psicologia Institucional (NEDPESP-DPSI) e outros da Fundação Oswaldo Cruz, ligados ao Instituto Oswaldo Cruz. Mantemos também constante diálogo com a Equipe de Psicologia do Trabalho e Clínica da Atividade, do Conservatoire National des Arts et Métiers - Paris, liderada por Yves Clot.

Detalhando um pouco mais a rede com quem mantemos relações de pesquisa, apresentamos brevemente os dois grupos mencionados. 
O grupo da UFES, o NEDPESP-DPSI, retoma o trabalho de Vigotski, de maneira indireta, a partir de Yves Clot, na contramão das leituras hegemônicas que reduzem Vigotski a um mero contraponto à psicologia de Piaget. Seus pesquisadores consideram o conceito de atividade como um instrumento crucial ao desenvolvimento da psicologia sob um paradigma ético-estético, retomando a inspiração fundamental de Vigotski em Baruch de Espinosa, por meio do filósofo Gilles Deleuze. Vigotski é, para esse grupo de pesquisa, menos uma referência bem delimitada na psicologia e mais uma inspiração a promover diálogos e cruzamentos entre diversas linhas de saber e práticas que constituem e questionam o campo psi. Compõem esse grupo a professora Maria Elizabeth Barros de Barros e colaboradores.

Os projetos do grupo de pesquisa do IOC/Fiocruz são voltados para aspectos da organização do trabalho do ponto de vista das relações saúde-ambiente no contexto hospitalar. Têm sido privilegiados temas como o trabalho noturno e as longas jornadas de trabalho que prevalecem entre os profissionais da enfermagem; as relações entre gênero (feminino e masculino), trabalho e saúde, estudadas com base em instrumentos e estratégias metodológicas que convergem para a ideia de regulação do tempo como categoria central da vida humana; estratégias de restituição de resultados de estudos epidemiológicos, com fins de ampliar os efeitos de participação dos trabalhadores de saúde nesses estudos. Para tanto, têm sido usados métodos da clínica da atividade. Compõem esse grupo a professora Lucia Rotenberg e colaboradores.

O Nutras comporta outras linhas de pesquisa que têm o trabalho como objeto empírico e conceito central, destacando o conceito de atividade tal como nas pesquisas orientadas pelo professor Hélder Muniz.

Fora desse núcleo de pesquisa, no Programa de Pós-Graduação em Psicologia da UFF, a forte referência a Espinosa aproxima nossa linha de pesquisa e nosso interesse nos estudos de Vigotski a outros grupos com diferentes eixos teórico-metodológicos.

Voltamos agora à linha de pesquisa do Nutras, que estuda atualmente o trabalho como operador de saúde e busca desenvolver métodos de pesquisa-intervenção no campo da análise do trabalho. Nessa linha de estudo, as principais referências teóricas são a clínica da atividade (CLOT, 2010) e a análise institucional de linha francesa (LOURAU, 1993). O principal elo entre as duas está na proposição de transformar para conhecer. O que nos leva, afinal, a buscar ampliar nosso diálogo com as proposições de Vigotski, tomando o conceito de desenvolvimento como central em psicologia do trabalho.

\section{Transformar para conhecer}

Nas décadas de 1920-1930, Vigotski enfatizou "que todos os fenômenos sejam estudados como processos em movimento e em mudança" (VIGOTSKY, 2002, p. 8). De acordo com o autor, há uma relação inexorável entre objeto e método de investigação que constituem o processo de construção do conhecimento científico. Desse modo, a construção do método é, ao mesmo tempo, premissa e produto, ferramenta e resultado da investigação, sendo fundamental o refinamento do olhar do pesquisador para a construção da trilha metodológica. O pesquisador analisa processos e movimentos. Em vez de isolar elementos a serem conhecidos, a metodologia da psicologia histórico-cultural opta pelo foco nas relações, que viabiliza a compreensão da totalidade. Ela estuda os fenômenos na história, ou seja, movimentos de recriação da realidade que se dá através de mudanças nas relações entre as partes (ZANELLA et al., 2007).

A partir dessa compreensão, a clínica da atividade elege como objeto de análise a história do desenvolvimento da atividade de trabalho, com suas possibilidades e seus empecilhos. Isso significa, no âmbito da relação objeto/método, possibilitar a criação de métodos que, ao provocar uma experiência de confrontação com os meios de trabalho, buscam provocar o desenvolvimento, possibilitando aos trabalhadores viver novas experiências. Trata-se de um método:

Concebido, não para saber o que são, mas para experimentar, com eles, o que poderiam vir a ser. Em vez de procurar a explicação do que é eterno, a psicologia de Vigotski tenta encontrar as condições gerais mediante as quais se produz algo de novo (CLOT, 2010, p. 63-64, grifo do autor).

O foco no movimento e nas relações se apresenta na análise feita por Vigotski da constituição do pensamento verbal como uma relação entre pensamento e linguagem (ZANELLA et al., 2007). O uso de signos, como na fala, tem uma função organizadora que invade o processo de uso dos instrumentos, produzindo novas formas de comportamento e percepção. De acordo com Vigotski, a criança começa a controlar o ambiente com a ajuda da fala, o que produz novas relações com o ambiente e com relação a seu próprio comportamento.

[...] as crianças resolvem suas tarefas práticas com a ajuda da fala, assim como dos olhos e das mãos. Essa unidade de percepção, fala e ação, que, em última instância, provoca a internalização do campo visual, constitui o objeto central de qualquer análise da origem das formas caracteristicamente humanas de comportamento (VIGOTSKI, 2002, p. 35).

Quando a criança se encontra diante de um problema prático, utiliza a fala para sua resolução, uso que se torna mais intenso quanto mais complicada é a situação. Nesse contexto, qualquer tentativa de impedir a fala da criança corre o risco de paralisá-la. Diferente da percepção no animal, a criança percebe o mundo não somente através dos olhos, mas também através da fala, que adquire uma função sintetizadora. Considerando a fala como produtora de novos modos de percepção, é possível compreender que a transformação e o desenvolvimento dialógico geram novos modos de conhecer e sentir, que, por sua vez, serão essenciais para a criação de novas possibilidades de ação.

Para Vigotski, o pensamento sempre se encontra em processo de desenvolvimento e transformação por meio do uso e da invenção de instrumentos semióticos. O desenvolvimento implica a atividade humana inserida na história e mediada pela cultura. Considerando a relação intrínseca entre pensamento e linguagem, é possível 
compreender o sujeito como um ser heterogêneo que vive constantemente um diálogo interior. Desse modo, a metodologia da clínica da atividade busca, por meio da abertura deste diálogo, gerar novas formas de percepção e mudança na relação do sujeito no âmbito da atividade profissional. Para tal, é indispensável a mobilização do coletivo de trabalho, considerando que "a abertura ao diálogo interior não pode manter-se sem relé social que o alimenta em energia conflitante" (CLOT, 2010, p. 33).

A clínica da atividade apresenta métodos que estimulam e transformam o diálogo entre os trabalhadores, o que desenvolve a atividade, produzindo a transformação no meio de trabalho. O exercício de uma clínica da atividade supõe a instalação proposital de um dispositivo desenvolvimental: a organização de uma nova atividade se superpõe à atividade ordinária que se busca transformar e compreender, ou melhor, transformar como indispensável para compreender.

No campo do trabalho, o interesse da tradição ergonômica francofônica (BÉGUIN; WEIL-FASSINA, 1997) está em insistir no fato que compreender se destina a transformar. O que nós descobrimos é talvez a profundidade do que aí se levanta. Isso porque, para compreender o que buscamos compreender, é preciso transformar (CLOT, 2004, p. 7).

$\mathrm{Na}$ metodologia históricodesenvolvimental, retomamos a diferença feita por Vigotski (1996) entre comportamento realizado e desenvolvimento possível. O comportamento é um sistema de reações que foram vencedoras entre diferentes ações possíveis naquela situação. Aquilo que é realizado é apenas uma parte ínfima do que seria possível fazer. "Mas essas possibilidades abandonadas - que não são diretamente acessíveis, nem pelo sujeito nem por seu interlocutor - não deixam de agir" (CLOT, 2004, p. 7). Para retomá-las é preciso adotar uma metodologia indireta, que consiste em tornar "a experiência vivida de um objeto em objeto de uma nova experiência vivida" (VIGOTSKI, 1925 apud CLOT, 2004, p. 7).

\section{A metodologia em clínica da atividade e o método da oficina de fotos}

A metodologia em clínica da atividade visa a produzir conhecimento sobre o desenvolvimento humano, provocando o desenvolvimento do poder de agir dos trabalhadores.

Propõe-se nessa metodologia uma forma de coanálise do trabalho, praticada no ambiente laboral. Nessa concepção, a pesquisa acerca do trabalho é sempre clínica, no sentido de que é situada, mas também nos sentidos de que deve produzir efeitos de desenvolvimento de recursos para a ação e de que o trabalhador é protagonista nessa coanálise.

A metodologia da clínica da atividade objetiva desenvolver e conhecer os meios de ação do ofício pesquisado, que são um patrimônio coletivo e transpessoal (CLOT, 2010). Considerando que esses processos de desenvolvimento dos meios de ação não são diretamente observáveis, utilizam-se métodos indiretos de análise. Busca-se analisar marcas do trabalho, que, nos estudos do NUTRAS, tem sido fotografias dos trabalhadores em atividade (OSORIO, 2010; OSORIO DA SILVA, 2011). Tanto na fabricação quanto na análise do material produzido, o trabalhador cujo ofício está em foco deve ser o protagonista da análise, sendo aí secundado pelo psicólogo. Por meio do diálogo, o psicólogo, como novo interlocutor, busca mobilizar a experiência estabilizada como meio de viver novas experiências e desenvolver novos recursos para a ação. De acordo com essa perspectiva, é preciso desenvolver o diálogo tornando-se ativo em seu exercício. No processo de apropriação da alteridade que nos afeta, é possível transformar a passividade em atividade.

A metodologia da clínica da atividade tem como um de seus fundamentos a distinção entre a atividade realizada e o real da atividade. Essa diferenciação remonta a clássica diferença entre tarefa e atividade (OMBREDANE; FAVERGE, 1955), considerando tarefa como o trabalho prescrito e a atividade como tudo aquilo que se faz para alcançar o prescrito. A atividade (de trabalho) é sempre mais do que a simples atividade realizada, observável diretamente, mensurável para fins de avaliação de produtividade. $\mathrm{O}$ conceito e, portanto, a análise da atividade, inclui, além do que é efetivamente realizado, o que não é feito, o que é feito para não fazer, o que se gostaria de fazer e o que deveria ser feito. Munidos dessa concepção do trabalhar, analisamos a atividade que se realiza como atividade situada, coletiva e necessariamente inovadora, o que não impede que seja por vezes limitada em sua capacidade de desenvolvimento.

Enquanto o real da atividade abarca diversas possibilidades, a atividade realizada é o resultado do conflito entre as várias atividades possíveis e rivais. Aquilo que se pode observar como a atividade do trabalhador é, na verdade, o conjunto de atividades que venceram o conflito entre as atividades possíveis. Contudo, as atividades inibidas, que são de fundamental importância para a compreensão da atividade realizada, não são observáveis diretamente. Desse modo, o trabalho real deve ser enfocado através de métodos indiretos.

Ao considerar o real da atividade e não somente a atividade realizada, o método indireto abrange os conflitos vitais inerentes ao trabalho, que podem tornar (ou não) seu desenvolvimento possível (CLOT, 2010). Uma vez que uma determinada ação passa pelo crivo do pensamento, esta se transforma em outra ação, que funciona como uma réplica da experiência, uma ação do trabalhador sobre a sua própria atividade. Considerando a mediação do pensamento pela linguagem, essa ação se efetua no meio social, através de uma metodologia dialógica.

Segundo Vigotski, a atividade humana é necessariamente mediada. Este conceito de atividade remete ao conceito de trabalho humano, tal como proposto pela teoria marxista. De acordo com a perspectiva dialética, o trabalho é mediatizado pelos instrumentos, que, por sua vez, são um produto historicamente construído da atividade social humana. Esses instrumentos podem ser de natureza física, como no caso de ferramentas que modificam o meio físico; e representacional, que seriam os signos que incidem e modificam a relação do homem consigo mesmo e com os outros homens (ZANELLA et al., 2007).

Fractal, Rev. Psicol., v. 27 - n. 1, p. 12-15, 2015 
Os signos são um importante exemplo de mediadores da atividade. No caso da linguagem oral, o signo da fala deve ser partilhado socialmente para que seja compreendido em uma construção coletiva de sentido. "[...] de acordo com a perspectiva vygotskiana, o nosso contato com o mundo físico e social não é direto, é na verdade marcado por aquilo que significamos desse próprio mundo" (ZANELLA, 2007, p. 77), o que cria uma relação indireta da pessoa com a realidade, marcada pelas experiências e possibilidades.

Nos métodos propostos em clínica da atividade, pode-se considerar como mediadores a fala, no debate gerado entre trabalhadores, entre trabalhadores e seu trabalho e entre trabalhadores e psicólogo; e o psicólogo, que, como novo interlocutor, pode ser um potente deflagrador de novos sentidos para diferentes aspectos do trabalho. Além disso, os registros usados para produzir marcas do trabalho também podem ser signos mediadores da atividade sobre a atividade (de trabalho) que se dá na intervenção. Esses registros, no caso do Nutras, têm sido as fotos. Em nosso trabalho, utilizamos, em certa ocasião, diagramas da atividade que resultou em acidente (OSORIO; CLOT, 2010). Já na França, a equipe de clínica da atividade tem trabalhado com vídeos e registros de voz (CLOT, 2010).

Nas oficinas de fotos (OSORIO, 2010; OSORIO DA SILVA, 2011) são produzidas imagens do ambiente de trabalho diretamente pelos trabalhadores. As fotos tomadas pelos trabalhadores são levadas às duplas para serem exibidas e analisadas. $\mathrm{O}$ trabalhador assume, empunhando a máquina fotográfica, um certo protagonismo no trabalho de análise: ele "dirige" a produção das imagens. Em alguns casos, as fotos são feitas com uma única máquina para um pequeno grupo. Nesse modo de funcionar, vários debates entre pares são necessários também nessa etapa, para decidir o que e como fotografar.

$\mathrm{Na}$ tomada das fotos existem diálogos reais e virtuais em curso. O diálogo interior que já vinha sendo provocado pela observação inicial do pesquisador se reativa, mediado pela máquina fotográfica. No momento seguinte, em que as fotos produzidas são exibidas para o pesquisador e os pares, uma nova etapa de observação e de diálogo real e virtual entra em cena. O pesquisador e os trabalhadores travam um diálogo sobre situações já familiares que os trabalhadores selecionam para pôr em análise. A partir dessas marcas do trabalho, o profissional se observa e assume uma posição de protagonismo diante de sua atividade. O pesquisador, nesse cenário, atua como coadjuvante, ou seja, como um dos instrumentos mediadores da análise.

Por meio do diálogo, o psicólogo, como novo interlocutor, busca mobilizar a experiência estabilizada como meio de viver novas experiências e desenvolver novos recursos para a ação. Através dos comentários sobre o material registrado - em vídeo, em foto ou outro meio - cada trabalhador observa, na atividade do outro, a própria atividade, reencontrando-a, mas sem reconhecê-la completamente. Com o foco naquilo que não converge entre as observações, a ativi- dade do pesquisador consiste em acompanhar tais dissonâncias e auxiliar os trabalhadores na comunicação do difícil de dizer, que toca o real da atividade.

\section{Comentários finais}

No percurso exposto, não temos dúvidas acerca da importância das proposições de Vigotski para nosso trabalho. Alguns temas e conceitos são ainda pouco estudados por nós, deixando zonas a serem exploradas. Esse é, por exemplo, o caso das noções de sujeito, de consciente e inconsciente em Vigotski. O conceito de zona proximal de desenvolvimento, apropriado por Clot como zona de desenvolvimento potencial, também não foi ainda suficiente estudado por nós.

De modo mais geral, nos perguntamos: que possibilidades insuspeitadas essa psicologia do desenvolvimento, tomada para pensar o desenvolvimento adulto, ainda irá nos apresentar?

\section{Referências}

BAKHTIN, M. Os gêneros do discurso. In: Estética da criação verbal. São Paulo: Martins Fontes, 2006. p. 261-306.

CANGUILHEM, G. O normal e o patológico. Rio de Janeiro: Forense Universitária, 2012.

CLOT, Y. Trabalho e Poder de Agir. Belo Horizonte: Fabrefactum, 2010.

CLOT, Y. Le travail entre fonctionnement et développement. Bulletin de Psychologie, [S.1.], v. 57 n. 1, p 5-12, 2004.

LOURAU, R. Análise institucional e práticas de pesquisa. Rio de Janeiro: UERJ, 1993.

OMBREDANE, A.; FAVERGE, J-M. L'analyse $d u$ travail. Paris: PUF, 1955.

OSORIO, C. Experimentando a fotografia como ferramenta de análise da atividade de trabalho. Revista Informática na Educação: teoria e prática, [S.1.], v. 13 n 1 jan./jun, p. 41-49, 2010.

OSORIO DA SILVA, C. A fotografia como uma marca do trabalho: um método que convoca o protagonismo do trabalhador na invenção de mundo. In: ZANELLA, A.; TITTONI, J. (Org.). Imagens no pesquisar: experimentações. Porto Alegre: Dom Quixote, 2011. p. 211-226.

OSORIO, C.; CLOT, Y. L'analyse collective des accidents du travail: une méthode d'analyse pour intégrer la dimension subjective et développer le genre professionnel. Activités Revue Electronique, [S.1.], v. 7, p. 28-41, 2010.

PRESTES, Z. Quando não é quase a mesma coisa: tradução de Lev Semionovitch Vigotski no Brasil. Campinas, SP: Autores Associados, 2012.

VIGOTSKY, L. S. Teoria e Método em Psicologia. São Paulo: Martins Fontes, 1996.

VIGOTSKY, L. S. Formação Social da Mente. São Paulo: Marins Fontes, 2002.

VIGOTSKY, L. S. Imaginação e Criação na Infância. São Paulo: Ática, 2009.

WISNER, A. Réflexions sur l'Ergonomie. Toulouse: Octarés, 1995.

ZANELLA, A. V. et al. Questões de método em textos de Vigotski: contribuições à pesquisa em psicologia. Psicologia e Sociedade, [S.1.], v. 19, n. 2, p. 25-33, 2007.

Recebido em: 29 de agosto de 2013

Aceito em: 03 de setembro de 2014 